Published in final edited form as:

Cell Tissue Res. 2017 March ; 367(3): 643-649. doi:10.1007/s00441-016-2539-y.

\title{
Pulmonary Vascular Remodeling in Pulmonary Hypertension
}

\author{
Rubin M. Tuder, MD \\ Program in Translational Lung Research, Division of Pulmonary Sciences and Critical Care \\ Medicine, Department of Medicine, Anschutz Medical Campus Research 2, Room 9001, \\ University of Colorado School of Medicine, 12700 East 19th , Avenue, Aurora, CO 80045
}

\begin{abstract}
Pulmonary vascular remodeling is the key structural alteration in pulmonary hypertension. This process involves changes in intima, media, and adventitia, often with the interplay of inflammatory cells. We review the pathology of these changes and highlight some of the pathogenetic mechanisms that underlie the remodeling process.
\end{abstract}

\section{Keywords}

Pulmonary hypertension; pulmonary remodeling; endothelial cells; smooth muscle cells; lung

Pulmonary hypertension $(\mathrm{PH})$ refers to hemodynamic alterations of the pulmonary circulation in which the pulmonary artery pressures are in excess of $25 \mathrm{~mm} \mathrm{Hg}$ - largely the result of the ground breaking introduction of pulmonary catheterization in the late 40's in the past century (Fishman 1997). In this setting, the pulmonary arteries and veins undergo several structural alterations that have been recognized as pulmonary vascular remodeling. These structural alterations, though similar when recognized (and quantified) in pathological specimens, are likely heterogeneous molecularly. Pulmonary vascular remodeling is the result, and, likely, contributes to increased pulmonary vascular pressures by increasing pulmonary vascular resistance.

The pathology of $\mathrm{PH}$ has been summarized in all five international meetings held thus far, which primarily targeted at how to classify the disease, to direct treatment, and diagnostic algorithms. The pulmonary vascular pathology most strongly influenced the first international PH conference in 1973, reflecting the contributions of several outstanding pathologists dedicated to studying the disease, like Wagenvoort, Reid, Edwards, and Heath (Heath and Wagenvoort 1975). The conferences that followed (Evian, France in 1998 (Haworth et al. 1998), Venice, Italy, in 2003 (Pietra et al. 2004), Dana Point, USA in 2008, and Nice, France in 2013 (Simonneau et al. 2004, Simonneau et al. 2013), while recognizing the relevance of the pathology of pulmonary vascular remodeling, largely restricted its description as means to a better understanding of the pathobiology of the disease (Tuder et al. 2013a). The present classification, formulated in Nice, France (Simonneau et al. 2013), is widely used to guide investigators in the field.0020

In prior reviews (Tuder and Erzurum 2009), we chose to segment pulmonary hypertension in regards to the levels of pulmonary artery pressures; mild to moderate, when in between 25 to $45 \mathrm{mmHg}$ and severe, when in excess of $45-50 \mathrm{mmHg}$. We acknowledge that this 
categorization is largely arbitrary, but, in our experience, it underscores that severe disease shares some distinct structural alterations of hypertensive pulmonary arteries, many of which are irreversible. This two-level characterization of $\mathrm{PH}$ reflects with reasonable accuracy the overall impact of $\mathrm{PH}$ on the right ventricle - right ventricular failure is ultimately the trigger of a patient's demise and physiological impairment.

But to fully appreciate the clinical and research importance of pulmonary vascular remodeling, it is imperative to examine the intricate relationship between normal pulmonary arterial physiology and macro and micro anatomy. In a recent review, we summarized several important insights on the normal pulmonary vascular structure, bringing to light anatomical and structural insights (which are now more than 50 years old) with a handful of three dimensional casting studies in animals and (some) humans (Tuder et al. 2013b). A single right ventricular beat normally propels approximately $500 \mathrm{ml}$ of stroke blood volume into the pulmonary arterial system, with approximately $140 \mathrm{ml}$ of blood in 277 billion capillaries (or about 10^11), occupying the equivalent of a tennis court size pulmonary gas exchange area. This extensive capillary network is supplied by $10^{\wedge} 8$ pulmonary vascular segments with 15-40 $\mu \mathrm{m}$ in diameter. A key characteristic of the loss of a well-defined pulmonary vascular media composed by smooth muscle cells in arteries smaller than $70 \mu \mathrm{m}$ in diameter: this structural characteristic may be teleologically critical to the requirement to be perfused at low pressures, a distinguishing feature of the pulmonary circulation vis-à-vis the systemic circulation.

Given the critical need to have a low capillary perfusion pressures for optimal gas exchange, one can envision the need for pulmonary vascular remodeling as means to dissipate (more) proximally (than the capillary bed) high pulmonary pressures. Where are these high pressures generated in an acutely hypoxic normal lung, such as during acute hypoxia (fraction of inspired $\mathrm{O} 2$ in air of less than 13\%)? The property of hypoxic pulmonary vasoconstriction (HPV) resides in specialized pulmonary smooth muscle cells (McMurtry et al. 1976), which can depolarize under alveolar hypoxia and have a surge of intracytoplasmic calcium (Sylvester et al. 2012). HPV appears to occur in arteries as large as $1.2 \mathrm{~mm}$ in the dog; subsequent studies outlined that HPV would occur in arteries of less than $50 \mu \mathrm{m}$ in diameter (in the dog) and approximately $80 \mu \mathrm{m}$ in the sheep (Sylvester et al. 2012). Interestingly, this wide range of arterial diameters includes those arterial segments that undergo pulmonary vascular remodeling in PH. It is therefore possible that the combined effects of excessive vasoconstriction and of cell autonomous growth (combined with lack of cell death) may ultimately account to the structural alterations of the pulmonary circulation in PH (Tuder et al. 2013b).

Chronic exposure to hypoxia (usually modeled by exposing animals at a FiO2 of $50 \%$ or $8900 \mathrm{~m}$ ) causes hypoxic PH. Due to HPV and/or superimposed release of growth factors, pulmonary arteries undergo excessive muscularization, with a predominance of media remodeling, with no or minimal intima remodeling. While there is debate over how the pulmonary artery remodels under chronic hypoxia, it is a valuable disease related process as it may relate to $\mathrm{PH}$ in association with hypoxic states, like high altitude and chronic obstructive pulmonary disease. However, hypoxic PH is largely of mild to moderate severity (see above). 
In the review, we describe the spectrum of pulmonary vascular remodeling in $\mathrm{PH}$, particularly of the group 1 disease, also named as pulmonary arterial hypertension (PAH) (Simonneau et al. 2013); moreover, we also extend these insights into (some) small animal models. We briefly outline approaches to quantify key structural/morphological alterations and the potential impact of these features (also referred as pulmonary vascular lesions (Pietra et al. 2004)) in disease pathogenesis and pulmonary arterial pressures. This discussion is framed in macroscopic and microscopic pulmonary vascular compartments of intima lined by endothelial cells, media composed largely by smooth muscle cells, and adventitia populated by fibroblasts and, in PH, by inflammatory cells. The readers are encouraged to complement the present reading with comprehensive reviews on pathobiology of PH (Archer et al. 2010, Schermuly et al. 2011, Tuder et al. 2013a).

\section{Pulmonary vascular remodeling in $\mathrm{PH}$}

\section{A. Intima remodeling (Figure 1)}

The intima represents an endothelial cell-thick interface between the muscular media and the flowing blood. In the pulmonary circulation, the intima provides a vast surface area of unobstructed flow, therefore contributing to relatively low perfusion pressures, which is the trademark of the pulmonary circulation. In fact, the combined intima surface area of pulmonary arteries in the range of $20-30 \mu \mathrm{m}$ in diameter is of 2-3 logs that of more proximal pulmonary arterial segments (Tuder et al. 2013b).

The extent that the intima is compromised in PH is unknown. In a recent study, we demonstrated that, based on cross sections of pulmonary arteries, normal intima represented approximately $10 \%$ on the overall thickness; these findings are in line with prior studies of the pathology of idiopathic pulmonary arterial hypertension (IPAH), the paradigmatic example of severe PH (Chazova et al. 1995); in severe disease, lungs with PAH showed an approximately 3 -fold increase in intima fractional thickness (Stacher et al. 2012). Of note, this thickened intima would result in an approximately $1.5^{\wedge} 4$ (40-fold) increase in pulmonary vascular resistance. Interestingly, using the parameter of volume density with alveolar septa as reference, there is a doubling of PAH vs. control intima, overall within the range seen with another quantitative approach, of the measurement of intima fractional thickness (Stacher et al. 2012).

Interestingly, approximately $25 \%$ of lungs with PAH had intima thickening that overlapped the values seen in controls (normal lungs) (Stacher et al. 2012). As noted below, the overlap between media and adventitia fractional thickness between control and PAH pulmonary arteries was more pronounced than that seen with the intima.

The types of intima thickening are varied. They can be briefly summarized as based on the predominance of collagen and mucin, fibroblastic-like cells, or endothelial cells (Figure 1E). Endothelial-like cells, when proliferated in a disorganized fashion, form plexiform lesions (Figures 1B and D) (Tuder and Zaiman 2004). These are glomeruloid-like lesions, with variable formation of incipient blood vessels. Our prior studies demonstrated expression of markers of angiogenesis in these lesions (Tuder et al. 2001), including vascular endothelial growth factor (VEGF), VEGF receptors, and hypoxia inducible factor (HIF)-1a. Though its 
pathogenesis remains unclear, it is often seen in severe group $1 \mathrm{PAH}$ and in group 2 with $\mathrm{PH}$ associated with congenital heart malformations. Plexiform lesions are characteristic of IPAH morphology; moreover, they can be found in a significant number of cases of associated PAH (APAH, usually in the setting of collagen vascular diseases) (Stacher et al. 2012). Our data indicated that plexiform lesions were detected in $90 \%$ of lungs with PAH. There is a large variation of plexiform lesion profiles in a given lung and among PAH lungs; though it is tempting to speculate that plexiform lesions are the forerunners of occlusive intima lesions, no such correlation has been observed (Stacher et al. 2012).

Obliterative concentric lesions are characterized by an onion-skin arrangement of endothelial- and/or smooth muscle cells (Figure 1D). These lesions appear to be completely restricted to the pulmonary vascular lumen. Both plexiform and concentric lesions have been linked to IPAH (Heath and Edwards 1958); we confirmed the geographical association of concentric and plexiform lesion, with the former being present proximally to plexiform lesions, based on three-dimensional reconstruction studies (Cool et al. 1999).

Additional intima lesions consist of lesions characterized by being paucicellular, with increase in connective tissue, including extracellular matrix. Many appear to contain excessive amounts of mucopolysaccharides. How these lesions develop and their overall fate remain unclear; they have been probably referenced as intima fibrosis in prior pathological descriptions of $\mathrm{PH}$.

Interestingly, the intima fractional thickness, a measure of the extent of pulmonary artery intima contribution to the overall diameter, was significantly higher in IPAH pulmonary arteries when compared with APAH. Moreover, this index was also higher in lung of patients with documented mutations in bone morphogenetic protein receptor 2 (BMPR2) when compared with those with no identifiable mutations (Stacher et al. 2012). These novel findings appear to correlate with the clinical findings of more severe disease in patients with BMPR2 mutations and PAH.

\section{B. Media remodeling}

The media, composed predominantly of smooth muscle cells, has been the focus of prior pathological descriptions and pathophysiological studies in PH. Likely due to the properties of mediating HPV and the prominence of media remodeling in PH due to chronic hypoxia, PAH has been largely focused on studies targeting the media smooth muscle cell.

Prior studies delineated that normal media thickness corresponds to approximately 5\% (or less) of the overall pulmonary artery diameter (Chazova et al. 1995). Our data indicate that, control lungs, largely obtained from accidental deaths of younger adults, exhibit media fractional thickness was approximately 20\% (Stacher et al. 2012). The increase in PAH was approximately of $20 \%$ over that of control lungs. Remarkably, we found a significant overlap of media fractional thickness between $60 \%$ of PAH patients' lungs with control values (Stacher et al. 2012). These findings are of interest; they may reflect true differences between control population or sampling differences that may justify the observed differences. Moreover, if indeed there is a significant degree of shared medial pulmonary 
artery thickness between control lungs and those with severe PAH, then functional alterations become critical to explain how media remodeling contributes to the disease.

Of interest, the parameter of combined intima and media thickness correlated significantly with pulmonary artery pressures and pulmonary resistance. These findings might appear predictable, as with increased pulmonary artery pressures and pulmonary vascular resistance, there is an associated heightened media (and intima) remodeling (notwithstanding the degree of overlap with media thickness with control lungs). On the other hand, this finding also supports that the combined remodeling of both the intima and the media plays a role in the pathogenesis of pulmonary hypertension.

\section{Adventitia remodeling}

The remodeling of adventitia was one of the most prominent findings reported in an autopsy series of 19 patients with IPAH (Chazova et al. 1995). This study reported an increase in adventitia thickness of approximately 2 - to 4 -fold in IPAH lungs vs. controls. Similar prominent adventitia remodeling was noted in cows with Brisket's disease (enhanced susceptibility to severe $\mathrm{PH}$ and right ventricular failure due to grazing in high altitude) (Newman et al. 2011) and cows exposed to chronic hypoxia (simulated altitude of $17000 \mathrm{ft}$, i.e., fraction of inspired oxygen (FiO2) of 10\%) (Davie et al. 2006)

Our data however did not indicate that remodeled pulmonary arteries had more advanced adventitia remodeling than controls (with 98\% of patients with PAH overlapping with controls) (Stacher et al. 2012). However, it is conceivable that methodological limitations hamper how best measure adventitia remodeling. The precise boundaries of the adventitia impose a challenge for precise demarcation (at least in the human lung), and therefore introduces significant pitfalls for analyses; adventitia is largely composed of a connective tissue sheath that surrounds airways and pulmonary arteries. It contains lymphatic vessels and is the conduit of inflammation, either targeted at airways (like in bronchiolitis or asthma) or pulmonary arteries (like in pulmonary hypertension).

Notwithstanding the difficulties in analyzing the extent of adventitia remodeling in $\mathrm{PH}$, there is substantial evidence that the adventitia may play key roles as an inflammatory cell signaling hub (Pugliese et al. 2015, Stenmark et al. 2015). It acts as a signaling hub, holding feedforward interactions between resident fibroblasts and incoming macrophages. Moreover, the adventitia may act as a reservoir for bone marrow derived progenitors, which may directly or indirectly stimulate pulmonary vascular remodeling (Majka et al. 2008).

\section{Perivascular inflammation}

Given the prominence of pulmonary vascular remodeling, the component of inflammation remained largely on the side lines during the first more detailed descriptions of pulmonary vascular remodeling in PH (Bjornsson and Edwards 1985, Heath and Edwards 1958). However, there has been a growing interest in the findings, characterization, and functional studies regarding the role of inflammation in PH (Figure 1F).

The presence of macrophages and lymphocytes was highlighted in the early 90's (Tuder et al. 1994), suggesting that they may participate in the process of pulmonary vascular 
remodeling. Mast cells were recognized as participants of the structural findings in PAH (Caslin et al. 1990), confirmed in more recent studies (Savai et al. 2012).

Only more recently, perivascular remodeling was semi-quantitatively assessed and shown to correlate with hemodynamic parameters in PAH (Stacher et al. 2012); despite attempts to use volume density with alveolar septa as reference tissue, a semi-quantitative grading ranging from 0 (absent) to 3 (abundant) was used to generate an inflammatory score. Of note, there was a correlation between perivascular inflammation score with intima+media fractional thickness and a strong correlational trend with pulmonary artery pressures.

These studies were followed by an effort to better characterize the types of inflammatory cells in PAH lungs (Savai et al. 2012). This study confirmed that CD68+ macrophages, CD14+ monocytes, and dendritic cells do accumulate in the adventitia of remodeled pulmonary arteries in IPAH. Increases in all T lymphocyte populations, while with a decreased number of FoxP3 cells were noted in IPAH lungs vs. controls.

However, inflammation involves more than just the presence of inflammatory cells around remodeled pulmonary arteries in PH. Cytokines and chemokines are clearly drivers and contributors to perivascular inflammation in PH. IL-1 was recognized as a mediator of monocrotaline-induced rodent PH in the 90's (Voelkel et al. 1994), which was supported by observations in samples of patients with PAH (Humbert et al. 1995). These early observations led to a large set of new data linking inflammation to the pathobiology of PAH (Dorfmuller et al. 2003, Hassoun et al. 2009, Soon et al. 2010), some of which with a strong correlation with severity of disease (notably interleukin (IL) 6, IL8, IL20, and IL12) (Soon et al. 2010). Schistosomiasis-induced PAH is perhaps the paradigmatic entity in which a parasite, S. mansoni, triggers a TH-2 dominant response (Graham et al. 2010) and pulmonary vascular lesions identical to those seen in idiopathic PAH. Experimentally, the TH-2 inflammation leads to increased transforming growth factor (TGF)- $\beta 1$ (Kumar et al. 2015), which ultimately trigger pulmonary artery remodeling and PH. This process is largely dependent of thrombospondin-1 producing blood marrow monocytes (Kumar et al, unpublished). The aggregate of these data support, not only that inflammation is part of the pathology of $\mathrm{PH}$, but it may indeed drive several of the key pulmonary vascular lesions characteristic of the disease.

\section{E. Other pathological alterations present in $\mathrm{PH}$}

Old and recent clots are among the pathological alterations seen in PH lungs. They were reported in prior pathological assessments of the pulmonary circulation in PH (Palevsky et al. 1989), largely called thromboembolic primary pulmonary hypertension. However, this study reported significant thrombi in the group called "arteriopathy with plexiform lesions". We confirmed these findings in our series, with $50 \%$ detection of clots in remodeled pulmonary arteries (Stacher et al. 2012); a large number of these patients (42\%) were being anti-coagulated.

Although some unusual pathological findings can occur in lungs with PAH, including areas of alveolar exudates, granulomas, peribronchiolar inflammation. They are rather incidental and probably reflect underlying alternative diseases or exposures, unrelated to $\mathrm{PH}$. 


\section{How to analyze pulmonary vascular remodeling in $\mathrm{PH}$}

Notwithstanding the important contributions made by detailed, largely qualitative, descriptions of pulmonary vascular remodeling in PH (in fact, mostly PAH) (Bjornsson and Edwards 1985, Chazova et al. 1995, Heath and Edwards 1958, Pietra et al. 1989, Wagenvoort and Wagenvoort 1970), a stringent quantitative assessment of the pathology of severe PH remains to be done. Most of these prior studies are biased (i.e., contain analytical errors) due to inappropriate random and systematic sampling and lack of assessment of key stereological parameters (such as assessments of surface area and length). As summarized in excellent reviews (Hsia et al. 2010, Hyde et al. 2006, Muhlfeld and Ochs 2013), these approaches require a priori experimental planning and design and knowledge of fundamentals of stereology applied to organ samples. In fact, many of the current concepts of stereology, while founded by the seminal work of Weibel and collaborators (Weibel and GOMEZ 1962), were developed in the last 2 decades and require proper knowledge and training. These have been largely absent in the approaches in the pulmonary vascular field.

Recently, we summarized the importance of stereological methods to properly assess parameters of pulmonary vascular remodeling (Tuder 2014). Unfortunately, most of the current endpoints, including percent fully, partially, and nonmuscularized small, medium, and large pulmonary arteries or percent occluded arteries provide an unclear picture of pulmonary vascular remodeling due to errors (or biases) in their assessment. The parameter of $\%$ media thickening, which in fact conveys the volume density of media in relation to the overall arterial wall, is limited by the need of almost perfect cross sections. In our prior work (Stacher et al. 2012), we used volume of media and intima in relation to the volume of alveolar septa. This approach allowed us to analyze pulmonary arteries independent of their orientation and of the degree of lung inflation; we relied on the evidence that, in PAH, there is no evidence of alveolar destruction with emphysema. However, this assessment was limited by the lack of uniform random sampling of the entire lung, i.e., the data pertained to fragments of lungs obtained from specific regions as per protocol design. We propose that assessment of pulmonary vascular remodeling follows stereological rules (Muhlfeld and Ochs 2013), which will allow better correlation with pulmonary hemodynamics. This approach will generate more robust and stringent data, allowing better correlation with similar parameters obtained with the human diseased samples. Moreover, it will provide better quality data regarding interventions that can attenuate or overcome specific components of pulmonary vascular remodeling in $\mathrm{PH}$. These experimental advantages are particularly relevant to severe PAH, often modeled in rats that received the VEGF receptor blocker SU 5416 and exposed to chronic hypoxia (Taraseviciene-Stewart et al. 2001). This model shares intima remodeling with concentric and plexiform-like lesions (Abe et al. 2010) with human PAH.

\section{Conclusions}

There have been few attempts to properly quantify the pathological alterations in PAH lungs; this limitation also pertains to other forms of pulmonary hypertension, including the highly frequent Group 3, associated with interstitial lung disease and COPD. While the clinical advances in diagnosing and managing PAH do not require pathological support, updates in 
the classification (including changes in subgrouping) often rely on the pathology to cluster similar forms of the disease. There still remains the challenge of appropriately conducting stereological studies in lung with $\mathrm{PAH}$, which would require systematic random sampling (Tuder 2014).

\section{Acknowledgments}

Funding: This review has been supported by the grants R24 HL123767 and P01 HL014985-41A1.

\section{References}

Abe K, Toba M, Alzoubi A, Ito M, Fagan KA, Cool CD, Voelkel NF, McMurtry IF, Oka M. Formation of plexiform lesions in experimental severe pulmonary arterial hypertension. Circulation. 2010; 121:2747-2754. [PubMed: 20547927]

Archer SL, Weir EK, Wilkins MR. Basic Science of Pulmonary Arterial Hypertension for Clinicians: New Concepts and Experimental Therapies. Circulation. 2010; 121:2045-2066. [PubMed: 20458021]

Bjornsson J, Edwards WD. Primary pulmonary hypertension: a histopathologic study of 80 cases. Mayo Clin Proc. 1985; 60:16-25. [PubMed: 3965821]

Caslin AW, Heath D, Madden B, Yacoub M, Gosney JR, Smith P. The histopathology of 36 cases of plexogenic pulmonary arteriopathy. Histopathology. 1990; 16:9-19. [PubMed: 2307421]

Chazova I, Loyd JE, Newman JH, Belenkov Y, Meyrick B. Pulmonary artery adventitial changes and venous involvement in primary pulmonary hypertension. American Journal of Pathology. 1995; 146:389-397. [PubMed: 7856750]

Cool CD, Stewart JS, Werahera P, Miller GJ, Williams RL, Voelkel NF, Tuder RM. Three-dimensional reconstruction of pulmonary arteries in plexiform pulmonary hypertension using cell specific markers: evidence for a dynamic and heterogeneous process of pulmonary endothelial cell growth. American Journal of Pathology. 1999; 155:411-419. [PubMed: 10433934]

Davie NJ, Gerasimovskaya EV, Hofmeister SE, Richman AP, Jones PL, Reeves JT, Stenmark KR. Pulmonary artery adventitial fibroblasts cooperate with vasa vasorum endothelial cells to regulate vasa vasorum neovascularization - A process mediated by hypoxia and endothelin-1. American Journal of Pathology. 2006; 168:1793-1807. [PubMed: 16723696]

Dorfmuller P, Perros F, Balabanian K, Humbert M. Inflammation in pulmonary arterial hypertension. Eur Respir J. 2003; 22:358-363. [PubMed: 12952274]

Fishman, AP. A century of primary pulmonary hypertension. In: Rubin, LJ., Rich, S., editors. Primary pulmonary hypertension Lung biology in health and disease. Macel Decker; New York: 1997. p. $1-17$.

Graham BB, Bandeira AP, Morrell NW, Butrous G, Tuder RM. Schistosomiasis-associated pulmonary hypertension: pulmonary vascular disease: the global perspective. Chest. 2010; 137:20S-29S. [PubMed: 20522577]

Hassoun PM, Mouthon L, Barbera JA, Eddahibi S, Flores SC, Grimminger F, Jones PL, Maitland ML, Michelakis ED, Morrell NW, Newman JH, Rabinovitch M, Schermuly R, Stenmark KR, Voelkel NF, Yuan JX, Humbert M. Inflammation, growth factors, and pulmonary vascular remodeling. J Am Coll Cardiol. 2009; 54:S10-S19. [PubMed: 19555853]

Haworth, SG., Rabinovitch, M., Meyrick, B., Michel, R., Pietra, GG., Polak, JM., Reid, LM., Tuder, RM. Primary Pulmonary Hypertension: Executive Summary from the World Symposium-Primary Pulmonary Hypertension. Rich, S., editor. 1998. p. 2-5.

Heath D, Edwards JE. The pathology of hypertensive pulmonary vascular disease; a description of six grades of structural changes in the pulmonary arteries with special reference to congenital cardiac septal defects. Circulation. 1958; 18:533-547. [PubMed: 13573570]

Heath, D., Wagenvoort, CA. Classification and nomenclature. In: Hatano, S., Strasser, T., editors. Primary Pulmonary Hypertension: Report on a WHO meeting; October 15-17, 1973; Geneva: World Health Organizaiton; 1975. p. 15-17. 
Hsia CC, Hyde DM, Ochs M, Weibel ER. An official research policy statement of the American Thoracic Society/European Respiratory Society: standards for quantitative assessment of lung structure. Am J Respir Crit Care Med. 2010; 181:394-418. [PubMed: 20130146]

Humbert M, Monti G, Brenot F, Sitbon O, Portier A, Grangeot-Keros L, Duroux P, Galanaud P, Simonneau G, Emilie D. Increased interleukin-1 and interleukin-6 serum concentrations in severe primary pulmonary hypertension. American Journal of Respiratory \& Critical Care Medicine. 1995; 151:1628-1631. [PubMed: 7735624]

Hyde DM, Harkema JR, Tyler NK, Plopper CG. Design-based sampling and quantitation of the respiratory airways. Toxicol Pathol. 2006; 34:286-295. [PubMed: 16698728]

Kumar R, Mickael C, Chabon J, Gebreab L, Rutebemberwa A, Garcia AR, Koyanagi DE, Sanders L, Gandjeva A, Kearns MT, Barthel L, Janssen WJ, Mauad T, Bandeira A, Schmidt E, Tuder RM, Graham BB. The Causal Role of IL-4 and IL-13 in Schistosoma mansoni Pulmonary Hypertension. Am J Respir Crit Care Med. 2015; 192:998-1008. [PubMed: 26192556]

Majka SM, Skokan M, Wheeler L, Harral J, Gladson S, Burnham E, Loyd JE, Stenmark KR, VarellaGarcia M, West J. Evidence for cell fusion is absent in vascular lesions associated with pulmonary arterial hypertension. AJP - Lung Cellular and Molecular Physiology. 2008; 295:L1028-L1039. [PubMed: 18931051]

McMurtry IF, Davidson AB, Reeves JT, Grover RF. Inhibition of hypoxic pulmonary vasoconstriction by calcium antagonists in isolated rat lungs. Circ Res. 1976; 38:99-104.

Muhlfeld C, Ochs M. Quantitative microscopy of the lung: a problem-based approach. Part 2: stereological parameters and study designs in various diseases of the respiratory tract. Am J Physiol Lung Cell Mol Physiol. 2013; 305:L205-L221. [PubMed: 23709622]

Newman JH, Holt TN, Hedges LK, Womack B, Memon SS, Willers ED, Wheeler L, Phillips JA 3rd, Hamid R. High-altitude pulmonary hypertension in cattle (brisket disease): Candidate genes and gene expression profiling of peripheral blood mononuclear cells. Pulm Circ. 2011; 1:462-469. [PubMed: 22530101]

Palevsky HI, Schloo BL, Pietra GG, Weber KT, Janicki JS, Rubin E, Fishman AP. Primary pulmonary hypertension. vascular structure, morphometry, and responsiveness to vasodilator agents. Circulation. 1989; 80:1207-1221. [PubMed: 2805259]

Pietra GG, Capron F, Stewart S, Leone O, Humbert M, Robbins IM, Reid LM, Tuder RM. Pathologic assessment of vasculopathies in pulmonary hypertension. J Am Coll Cardiol. 2004; 43:25S-32S. [PubMed: 15194175]

Pietra GG, Edwards WD, Kay JM, Rich S, Kernis J, Schloo B, Ayres SM, Bergofsky EH, Brundage $\mathrm{BH}$, Detre KM. Histopathology of primary pulmonary hypertension. A qualitative and quantitative study of pulmonary blood vessels from 58 patients in the National Heart, Lung, and Blood Institute, Primary Pulmonary Hypertension Registry. Circulation. 1989; 80:1198-1206. [PubMed: 2805258]

Pugliese SC, Poth JM, Fini MA, Olschewski A, El Kasmi KC, Stenmark KR. The role of inflammation in hypoxic pulmonary hypertension: from cellular mechanisms to clinical phenotypes. Am J Physiol Lung Cell Mol Physiol. 2015; 308:L229-L252. [PubMed: 25416383]

Savai R, Pullamsetti SS, Kolbe J, Bieniek E, Voswinckel R, Fink L, Scheed A, Ritter C, Dahal BK, Vater A, Klussmann S, Ghofrani HA, Weissmann N, Klepetko W, Banat GA, Seeger W, Grimminger F, Schermuly RT. Immune and inflammatory cell involvement in the pathology of idiopathic pulmonary arterial hypertension. Am J Respir Crit Care Med. 2012; 186:897-908. [PubMed: 22955318]

Schermuly RT, Ghofrani HA, Wilkins MR, Grimminger F. Mechanisms of disease: pulmonary arterial hypertension. Nat Rev Cardiol. 2011

Simonneau G, Galie N, Rubin LJ, Langleben D, Seeger W, Domenighetti G, Gibbs S, Lebrec D, Speich R, Beghetti M, Rich S, Fishman A. Clinical classification of pulmonary hypertension. J Am Coll Cardiol. 2004; 43:5S-12S. [PubMed: 15194173]

Simonneau G, Gatzoulis MA, Adatia I, Celermajer D, Denton C, Ghofrani A, Gomez Sanchez MA, Krishna KR, Landzberg M, Machado RF, Olschewski H, Robbins IM, Souza R. Updated clinical classification of pulmonary hypertension. J Am Coll Cardiol. 2013; 62:D34-D41. [PubMed: 24355639] 
Soon E, Holmes AM, Treacy CM, Doughty NJ, Southgate L, Machado RD, Trembath RC, Jennings S, Barker L, Nicklin P, Walker C, Budd DC, Pepke-Zaba J, Morrell NW. Elevated levels of inflammatory cytokines predict survival in idiopathic and familial pulmonary arterial hypertension. Circulation. 2010; 122:920-927. [PubMed: 20713898]

Stacher E, Graham BB, Hunt JM, Gandjeva A, Groshong SD, McLaughlin VV, Jessup M, Grizzle WE, Aldred MA, Cool CD, Tuder RM. Modern age pathology of pulmonary arterial hypertension. Am J Respir Crit Care Med. 2012; 186:261-272. [PubMed: 22679007]

Stenmark KR, Tuder RM, El Kasmi KC. Metabolic reprogramming and inflammation act in concert to control vascular remodeling in hypoxic pulmonary hypertension. J Appl Physiol 1985. 2015; 119:1164-1172. [PubMed: 25930027]

Sylvester JT, Shimoda LA, Aaronson PI, Ward JP. Hypoxic pulmonary vasoconstriction. Physiol Rev. 2012; 92:367-520. [PubMed: 22298659]

Taraseviciene-Stewart L, Kasahara Y, Alger L, Hirth P, Mc Mahon GG, Waltenberger J, Voelkel NF, Tuder RM. Inhibition of the VEGF receptor 2 combined with chronic hypoxia causes cell deathdependent pulmonary endothelial cell proliferation and severe pulmonary hypertension. Faseb Journal. 2001; 15:427-438. [PubMed: 11156958]

Tuder RM. How do we measure pathology in PAH (lung and RV) and what does it tell us about the disease. Drug Discovery Today. 2014; 19:1257-1263. [PubMed: 24881780]

Tuder RM, Archer SL, Dorfmuller P, Erzurum SC, Guignabert C, Michelakis E, Rabinovitch M, Schermuly R, Stenmark KR, Morrell NW. Relevant issues in the pathology and pathobiology of pulmonary hypertension. J Am Coll Cardiol. 2013a; 62:D4-D12. [PubMed: 24355640]

Tuder RM, Chacon M, Alger LA, Wang J, Taraseviciene-Stewart L, Kasahara Y, Cool CD, Bishop AE, Geraci MW, Semenza GL, Yacoub M, Polak JM, Voelkel NF. Expression of angiogenesis-related molecules in plexiform lesions in severe pulmonary hypertension: evidence for a process of disordered angiogenesis. Journal of Pathology. 2001; 195:367-374. [PubMed: 11673836]

Tuder, RM., Erzurum, SC. Pulmonary endothelium and pulmonary hypertension. In: Voelkel, NF., Rounds, S., editors. The pulmonary endothelium: Function in health and disease. Wiley-Blackwell; Chichester: 2009. p. 449-460.

Tuder RM, Groves B, Badesch DB, Voelkel NF. Exuberant endothelial cell growth and elements of inflammation are present in plexiform lesions of pulmonary hypertension. Am J Pathol. 1994; 144:275-285. [PubMed: 7508683]

Tuder RM, Stacher E, Robinson J, Kumar R, Graham BB. Pathology of pulmonary hypertension. Clin Chest Med. 2013b; 34:639-650. [PubMed: 24267295]

Tuder, RM., Zaiman, AL. Pathology of pulmonary vascular disease. In: Peacock, A., Rubin, LJ., editors. Pulmonary circulation. Arnold; London: 2004. p. 25-32.

Voelkel NF, Tuder RM, Bridges J, Arend WP. Interleukin-1 receptor antagonist treatment reduces pulmonary hypertension generated in rats by monocrotaline. American Journal of Respiratory Cell and Molecular Biology. 1994; 11:664-675. [PubMed: 7946395]

Wagenvoort CA, Wagenvoort N. Primary pulmonary hypertension. A pathologic study of the lung vessels in 156 clinically diagnosed cases. Circulation. 1970; 42:1163-1184.

Weibel ER, GOMEZ DM. Architecture of the human lung. Use of quantitative methods establishes fundamental relations between size and number of lung structures. Science. 1962; 137:577-585. [PubMed: 14005590] 


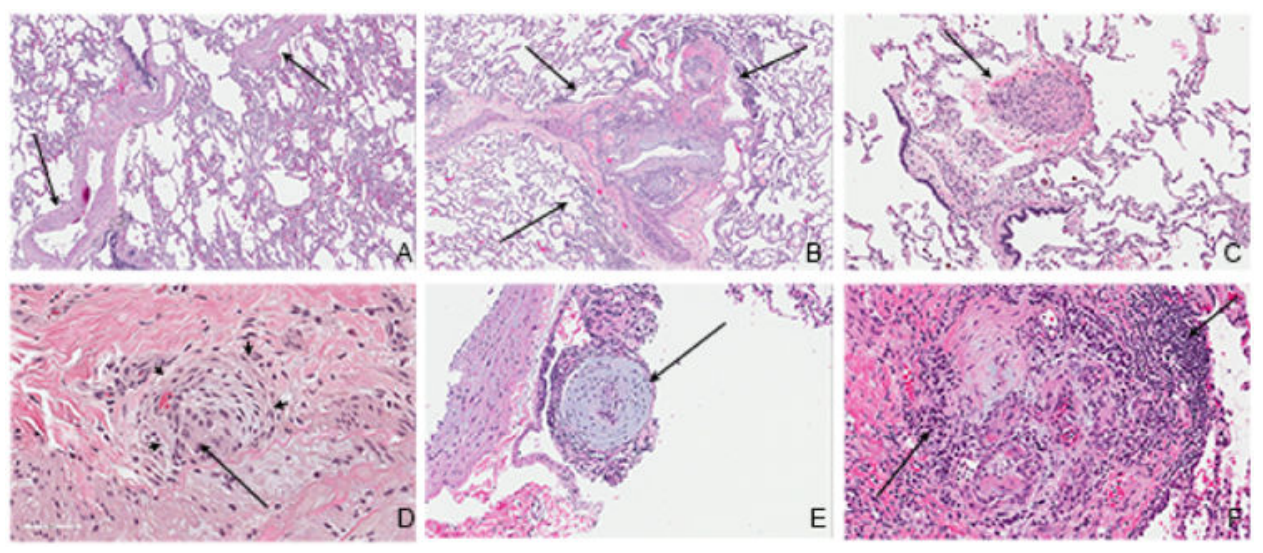

Figure 1.

A. Moderately thickened pulmonary arteries (arrows) in a normal lung, obtained as a potential graft.

B. Exuberant plexiform lesion (arrows) with whorls of endothelial cells with abnormally organized blood vessel lumina.

C. Pulmonary artery in PAH with marked intima obliteration (arrow).

D. Small cluster of endothelial cells, consistent with incipient plexiform lesion (arrow), surrounded by cells organized in concentric pattern (small arrows).

E. Pulmonary artery with cellular and mucoid intima thickening (arrow).

F. Marked inflammation around and within plexiform lesion (arrow). 